IMPLANT THERAPY OUTCOMES, SURGICAL ASPECTS

\section{Does implantoplasty interfere with implant resistance to fracture? - in vitro pilot study.}

BANACO D.* ; SANTOS D. ${ }^{* *}$; MESSIAS A. **; RAMOS J.C.**; FERREIRA J.M.F.; ${ }^{* \star *}$ MARTINS O. **

* Master's Student of Dental Sciences, Complutense University of Madrid

* Dentistry Department, Faculty of Medicine, University of Coimbra, Portug

${ }^{* * *}$ Department of Materials and Ceramics Engineering, University of Aveiro, Portugal

\section{Abstract}

Background: Peri-implantitis is an inflammatory disease associated with peri-implant Bone loss and microbiological implant surface contamination. Ressective surgery with mplantoplasty is one of the possible therapeutic approaches with favourable results. This procedure will remove implant structure and possibly will modify his resistance.

Aim/hypothesis: The aim of this study is to conduct a laboratory pre-clinical pilot study to determine the "n" required for a future study which aims to assess the resistance to fracture of implants that suffered implantoplasty.

Material and Methods: Six implants (Conical Bioneck TRI RP 4.3x13mm, EXAKTUS, Portugal) were randomly divided into two groups (Test group - implantoplasty $(n=3)$; Control group - without implantoplasty $(\mathrm{n}=3)$ ). All implants had healing abutments Crkansas bur were used to regularized and polished the imolants. The samples were fixed on a 30 o metal support and a continuous compression force (SHIMADZU CORPORATION, Kyoto, Japan) was applied on the abutment until the first fracture signal of the implant being detected by the software. Statistical analysis was calculated using the unpaired t test (QuickCalcs, Graphpad, USA).

Results: For the control group the average value (mean \pm standard deviation) of the forces (F) applied until fracture occurred was $1331,3 \pm 182,852 \mathrm{~N}$. For the test group the surface of the implant. Radiographic analysis was performed and it was possible to verify the malaptation between the anytment and the implant. Regarding $F$ results there were no inter-group statistically significant differences $(p=0.2182 ; 95 \% \mathrm{Cl})$.

Conclusion and Clinical Implications: Within the limitations of a preclinical study, (egarting to implant resistance to fracture, we can say that implants with implantoplasty tidn't show statistically significan tafferences compared to those without implantoplasty. The necessary " $n$ " to carry out a properly designed pre-clinical study is 13 Thplants/group.

\section{Background and Aim}

- Peri-implantitis $\Rightarrow$ inflammatory disease

- Peri-implant bone loss

Microbiological implant surface contamination

Implantoplasty

remove contaminated surface

- remove implant structure

- modify implant resistance

Aim:

- implant resistance to fracture after implantoplasty

determine the " $n$ " required for a future study

\section{Methods and Materials}

6 implants (Conical Bioneck TRI RP 4.3x13mm, EXAKTUS, Portugal)

- Test group (implantoplasty) + Control group (no implantoplasty)

$(n=3)$

- Included on a self-cure acrylic resin (Unifast Trad, GC EUROPE®)

6mm (included), $7 \mathrm{~mm}$ (non-included)

Healing abutments (Straight Healer, 3.5x5mm TRI, EXAKTUS®).

- Test Group

- Implantoplasty

- Cylindrical diamond bur $(151 \mu \mathrm{m})$

Arkansas bur

Control Group

No intervention

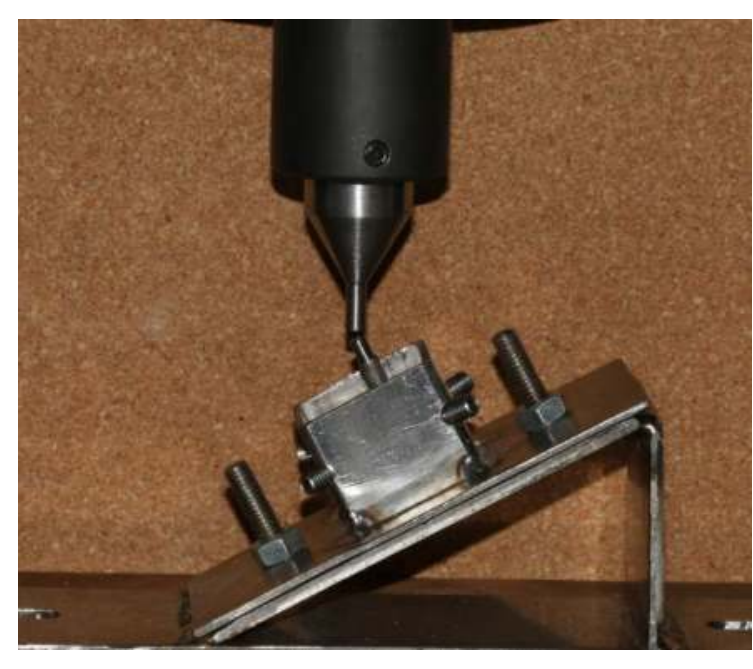

Fig. 1- Implant on a metal support $\left(30^{\circ}\right)$ to perform the compression tests

Compression tests

AG-IS, SHIMADZU, 10 kN; SHIMADZU CORPORATION, Kyoto, Japan)

$30^{\circ}$ metal support

Continuous compression force until fracture

Statistical analysis (QuickCalcs; Graphpad-GraphPad Software, Inc. USA)

Unpaired t test

\section{Results}

Fig. 2- Compression Test Results

\begin{tabular}{|c|c|c|c|}
\hline $\begin{array}{c}\text { Test Group } \\
(\mathbf{n}=3)\end{array}$ & Force (N) & $\begin{array}{c}\text { Control Group } \\
(\mathbf{n}=3)\end{array}$ & Force (N) \\
\hline T1 & 1083,4 & $\mathbf{C 1}$ & 1472,8 \\
\hline T2 & 707,03 & $\mathbf{C 2}$ & 1124,8 \\
\hline T3 & 1307,6 & $\mathbf{C 3}$ & 1396,3 \\
\hline $\begin{array}{c}\text { Mean and } \\
\text { Standard } \\
\text { Deviation }\end{array}$ & $1032,7 \pm 303,5$ & $\begin{array}{c}\text { Mean and } \\
\text { Standard } \\
\text { Deviation }\end{array}$ & $1331,3 \pm 182,8$ \\
\hline
\end{tabular}

Fig. 3- Representative curves of the evolution of the results of the compression tests

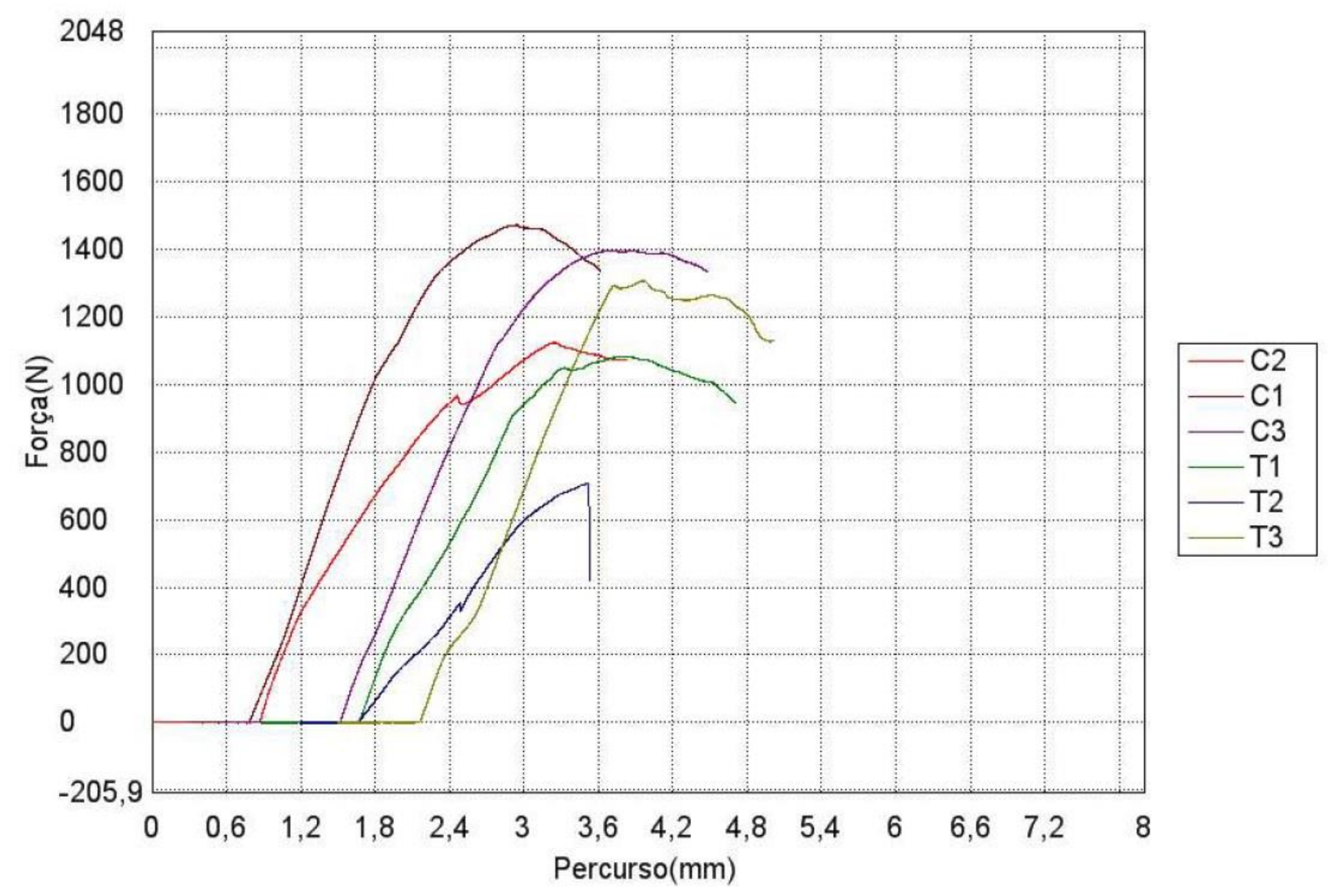

Fig. 4- Statistic Analysis

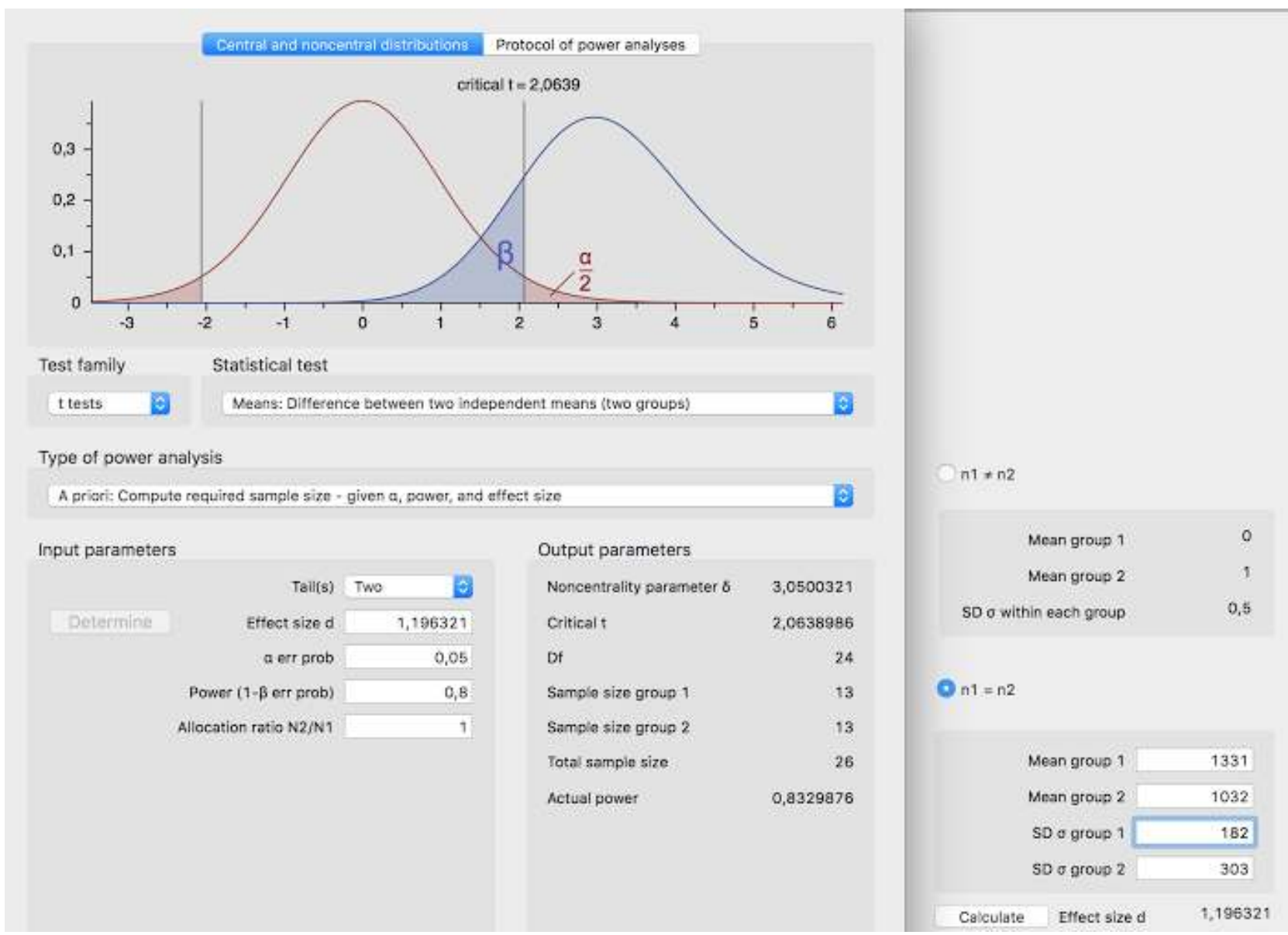

$\mathrm{p}=0,2182$ (confidence interval 95\%)

- No intergroup statistically significant differences

Future study should have a total sample of 26 elements Effect size: 1,2

\section{Conclusions}

Implant resistance after implantoplasty didn't show statistically significant differences compared to those without implantoplasty

- Necessary "n" to carry out a properly designed pre-clinical study 13 implants/group.

\section{References}

"Therapy of Peri-lmplantititis with Resective Surgery. A 3-Year Clinical Trial on Rough Screw-Shaped Oral Implants,
Part I: Clinical Outcome", Clin Oral Implants Res, 11 (2005), 9-18 "Therapy of Peri-Implantitis with Resective Surgery. A 3-Year Clinical Trial on Rough Screw-Shaped Oral Implants. 'Impact of Implantoplasty on Strength of the Implant-Abutment Complex', Int J Oral Maxillofac Implants, 28 (2013) 'Surface Roughness of Dental Implants and Treatment Time Using Six Different Implantoplasty Procedures', Clin 'Analysis of Implant Strength after Implantoplasty in Three Implant-Abutment Connection Designs: An in Vitro
Study' Int $\mathrm{J}$ Oral Maxillofac Implants, 31 (2016) 'Fracture Strength of Implant Abutments after Fatigue Testing: A Systematic Review and a Meta-Analysis', J Mech 